\title{
Initiation of Antiretroviral Therapy in HIV Elite Controller: A Case Report from Limpopo Province, South Africa
}

\author{
VM Muthambi ${ }^{1,2, *}$, KG Ndzeru ${ }^{3}$, NG Mbenenge ${ }^{4,5}$, and CG Adu-Gyamfi ${ }^{6}$ \\ ${ }^{1}$ National Health Laboratory Service, Polokwane, South Africa \\ ${ }^{2}$ Department of Medical Microbiology, University of Limpopo, Limpopo, South Africa \\ ${ }^{3}$ Voortrekker Hospital, Mokopane, South Africa \\ ${ }^{4}$ National Health Laboratory Service-Charlotte Maxeke Johannesburg Academic Hospital, Johannesburg, South Africa \\ ${ }^{5}$ Virology Department, Wits School of Pathology, University of Witwatersrand, Johannesburg, South Africa \\ ${ }^{6}$ Centre for Vaccines and Immunology, National Institute for Communicable Diseases, South Africa
}

*Corresponding author: Muthambi VM, Department of Medical Microbiology, University of Limpopo, Limpopo, South Africa; Tel: 015-297 1099/1101/1102; E-mail: vongani.muthambi@nhls.ac.za

Received: 03 May, 2021 | Accepted: 17 Jun, 2021 | Published: 28 Jun, 2021

Citation: Muthambi VM, Ndzeru KG, Mbenenge NG, Adu-Gyamfi CG (2021) Initiation of Antiretroviral Therapy in HIV Elite Controller: A Case Report from Limpopo Province, South Africa. J HIV AIDS 7(1): dx.doi.org/10.16966/2380-5536.181

Copyright: (C) 2021 Muthambi VM, et al. This is an open-access article distributed under the terms of the Creative Commons Attribution License, which permits unrestricted use, distribution, and reproduction in any medium, provided the original author and source are credited.

\section{Abstract}

Elite Controllers (ECS) are a less frequent but distinct group of HIV infected patients. Recent treatment guidelines encourage ART initiation in all HIV-infected individuals as early as 2 possible to control the infection and prevent transmission. Initiating ART in ECs remains controversial, although there are multiple hypothetical benefits. Currently, there is evidence that ECs must be initiated on ART in order to prevent non-AIDS related comorbidities associated with immune activation. Clinicians are to weigh the risks and benefits of initiating ART as well as monitor the patients for effective therapy. In this case report, we present an HIV management dilemma of an EC, a middle-class South African woman from the Limpopo province.

Keywords: Elite controllers; ART; ART initiation; Undetectable viral load; Viral load

Abbreviations: AIDS: Acquired Immunodeficiency Syndrome; ART: Antiretroviral Therapy; CRP: C-Reactive Protein; ECs: Elite Controllers; ESR: Erythrocyte Sedimentation Rate; PCR: Polymerase Chain Reaction; HIV: Human Immunodeficiency Virus; RNA: Ribonucleic Acid; TB: Tuberculosis

\section{Background}

Human Immunodeficiency Virus (HIV) infection is a life-long chronic condition. Early diagnosis imparts better HIV management that leads to reduce mortality [1]. In the majority of infected people, the sequence of HIV infection is less well defined. Still it comprises of the time from the acquisition and viral eclipse through seroconversion (early or primary HIV infection) then followed by a period of clinical latency as a result of antibody evolution. Acute HIV infection is characterized by a high viral load due to a highly replicating HIV and a decreased CD4 cell count which is usually above 500 cells per $\mathrm{ml}$. During clinical latency, there is persistent depletion of peripheral CD4 T cells, immune amplification, and inflammation [2,3]. In the Absence of Antiretroviral Therapy (ART), the patient will develop Acquired Immunodeficiency Syndrome (AIDS). A small subgroup $(<1 \%)$ of the HIV infected population, referred to as Elite Controllers (ECs), suppress HIV viremia below the limit of quantification of clinical viral load assays in the absence of ART [2-5]. The controlled viremia in ECs is primarily a result of host genetic and immune responses to the virus. ECs maintain a normal CD4 T cell count over a long period and thus are slow progressors to AIDS.
However, all is not entirely normal in these "privileged ones". Some studies have reported elevated levels of immune activation and persistent inflammation in ECs [6-8]. A sustained immune activation has been implicated in the increased non-AIDS defining disorder, including HIV-associated dementia, bone disorders and systemic organ failure among people living with HIV [7]. It is for these reasons that ECs should be considered for ART. The current treatment guideline suggests that all people with HIV infection be treated as early as possible to control the infection and prevent transmission, we present an HIV management dilemma of a South African HIV elite controller.

\section{Case Report}

A 53-year woman from Mokopane in the Limpopo province was diagnosed with HIV-1 infection in 2008. She attended her ART clinic regularly and was monitored at the HIV clinic for the past ten years. She was a wife and a mother of four children. Unfortunately, her husband passed away due to an undisclosed chronic illness in 2015. Her husband's HIV status was unknown to her. She had no significant medical history, except occasionally presenting with upper respiratory 
tract infections, which resolved without hospitalization. She also had no comorbid illness and no record related to the use of traditional medication. On physical examination, she looked healthy, stable and had no sign of illness. Her laboratory reports indicated that she had maintained viral load below the detectable limit, i.e., $<50$ copies per $\mathrm{ml}$ with a CD4 count above 500 cells/ $\mu \mathrm{l}$ since diagnosis (Figure 1 ). She tested negative for Hepatitis $\mathrm{B}$ and $\mathrm{C}$ infections.

In 2018, we confirmed her HIV status again by repeating two HIV ELISA tests according to the HIV diagnosis algorithm as HIV reactive with an optic density of above 250 for both assays (screening on Unicel DXI 800 using Bio-Rad Access HIV combo and confirmed on the Cobas e411 using Elecsys HIV combi PT). Additionally, an ultrasensitive quantitative HIV-1 polymerase chain reaction PCR assay was used, and it detected 16 HIV RNA copies per ml ( $<20$ HIV RNA copies per $\mathrm{ml})$.

Hematological tests showed a normal leukocyte count of $5.0 \times$ $109 \mathrm{~L}^{-1}$ (normal: 4.0-10.0 $\times 109 \mathrm{~L}^{-1}$ ) with a normal differential count and haemoglobin measurement of $10.2 \mathrm{~g} / \mathrm{dl}$ (normal: 8.7-11.2 g/dl). C-Reactive Protein (CRP) and Erythrocyte Sedimentation Rate (ESR) were not performed. The direct smear of spontaneously expectorated sputum was negative for acid-fast bacilli, and active TB was rule-out. A chest radiograph was normal. The 2016 South African HIV guidelines stipulated that all HIV positive individuals should be offered ART [911] however she was not initiated due to her confusing result. Upon consultation with the clinical team and the virologist, the patient was counselled and initiated on ART.

\section{Discussion and Conclusion}

Elite controllers are a minority subset of the HIV infected population who rarely progress to AIDS even without ART [4]. Currently, there exists scarce literature detailing the viral and immune dynamics in ECs. Recent studies have reported that even though ECs are infected with replication-competent HIV, they quarantine HIV in remote centres of their chromosomes and other sanctuary sites, rendering it slow or unable to replicate $[8,12]$. The ECs have been reported to experience viral rebound from these sanctuary sites, responsible for HIV viral blips occasionally observed in these privileged individuals [13]. About a third of ECs who experience viral blips end up with the loss of virological control $[14,15]$. Some studies have reported increased viral replication and T cell activation in ECs who experience viral rebounds

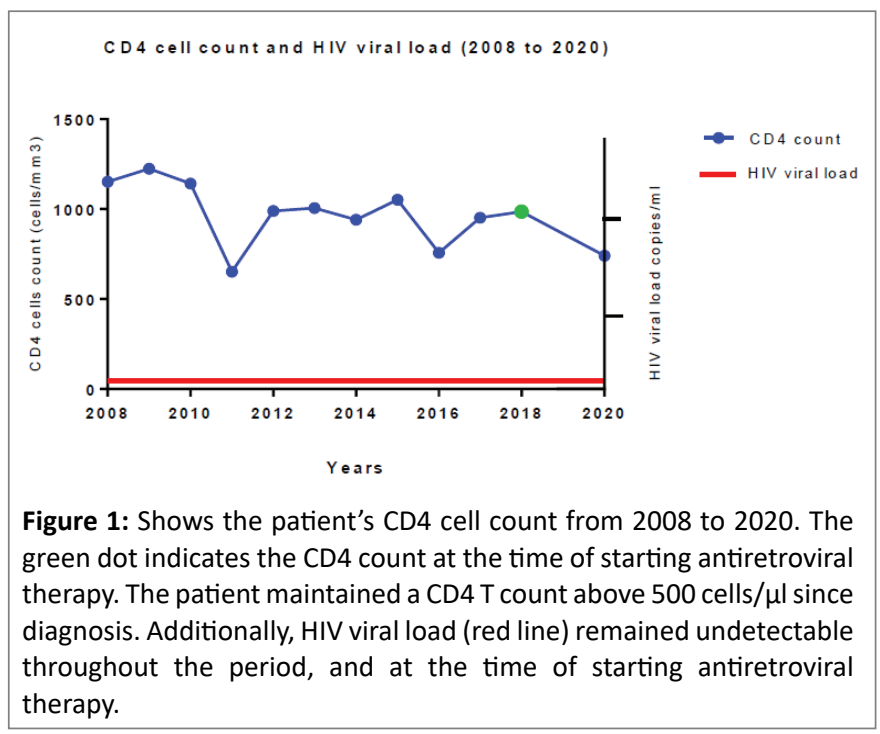

compared to non-controllers [8]. As a result, ECs possess the potential risk of HIV transmission, although this has never been reported so far. Clinically, ECs demonstrates Undetectable HIV viral loads in blood and slow progression to AIDS. However, HIV infected cells retain their ability to proliferate from sanctuary sites. The loss of virological control is associated with loss of immunological mediated control of the infection which may predispose ECs to HIV superinfection [16].

Currently, South Africa has one of the world's most extensive HIV test and treat programme and has seen significant achievements aligned with United Nations AIDS (UNAIDS) goals in ending the HIV epidemic [17]. Although there has been a massive improvement in ART availability with an increased number of HIV persons on treatment over the past decade, not every HIV infected person is on ART. The global action plan set out a 90-90-90 strategy to help end the HIV/AIDS pandemic, aiming to test at least $90 \%$ of all the people with HIV infection, place at least $90 \%$ of them on appropriate ART regimen and ensure that $90 \%$ of those on ART attain full viral suppression [18]. South Africa adopted this strategy [19].

Our patient remained asymptomatic without a history of HIV related disease or AIDS-defining illness even ten years after the HIV diagnosis. A study by Tiemessen CT, et al. in South Africa reported an average of $10 \%$ of the HIV-infected population maintains a stable CD 4 $\mathrm{T}$ cell count of over 500 cells $/ \mu$ l for at least five to ten years without ART [8]. Our patient classically fit in this group. The guidelines are not explicit about ART initiation in ECs and HIV management in the context of a suppressed baseline HIV viral load. The lack of treatment guidelines on initiating ECs on ART poses a dilemma for the healthcare workers. Firstly, the clinical conundrum of taking medication with side effects and potential toxicities requires more attention and understanding from the patients to improve treatment adherence. Secondly, ECs have difficulties understanding the need for ART as their viral load remains suppressed. Several studies have reported poor ART adherence among ECs [10, 20-22].

Our patient was initiated on ART even though it is controversial. However, there are multiple theoretical benefits to both the patient and the HIV control program. ART is beneficial in preventing HIV transmission, HIV-associated non-AIDS related complications and other co-morbidities [23]. A handful of studies have reported treatment of ECs has potential advantages of minimizing the size of the HIV reservoir, thus diminish the risk of transmission and dampening immune activation [22-24]. The controversy stem from a study by Okulicz JF, et al., the researchers reported a marginal increase in CD4 $\mathrm{T}$ cell count among ECs, however, this relative increase was small compared with non-controllers [25]. Furthermore, in a case report by Sedaghat AR, et al, they also observed a dip in CD4 T cell count after initiating ART in an ECs [26]. But broad evidence available indicates a higher level of T cell activation in ECs compared to non-controllers and healthy controls $[6,23,27]$.

Regarding initiating ECs on ART, a thorough review of literature by Noel et al., again emphasize the heterogeneity among this group of patients [23]. Currently, there is an urgent need for a precise standardized stratification of controllers so that accurate markers of HIV reservoir may be used to identify ECs at low risk of disease progression to influence ART implementation. Additionally, another important consideration is the willingness of the individual to begin a life-long ART. A recent report by Li JZ, et al. indicates the majority of ECs refused to initiate ART mostly due to concerns about drug toxicities [28]. ECs can be monitored if they are unwilling to be on treatment but when they begin to have viral blips or decreased CD4 T 
cell count ART can then be initiated It is also important to take into account that ECs might progress to severe HIV disease without a prior increase in viral load.

Lastly, one major concern is immunological and virological monitoring of ECs on ART. The use of ultra-sensitive viral load assay is expensive and located in specialized or reference laboratories. Understanding the mechanisms responsible for the exceptional control and development of novel assays to monitor the progress of treatment in ECs remains crucial.

In conclusion, even though ECs are a rare group among the HIV infected population in South Africa, there exist virtually no information about initiating and monitoring ART in this group. Nonetheless, initiating ART in ECs should be based on virological and immunological indicators these patients. There is currently no data about the long term survival of ECs on ART regimen. Research is needed to guide the management of HIV infection in the ECs.

\section{Acknowledgement}

This work is to the memory of the late Mr Paul Dikgote (Laboratory Manager, National Health Laboratory Service- Potgietersrust). We are also grateful to all staff of the Centre for HIV and STI, Cell Biology Section, National Institute for Communicable Diseases, Johannesburg for their various contributions.

\section{Conflict of Interest}

The authors report no competing interest in this work.

\section{References}

1. Lee K, Park HD, Kang ES (2013) Reduction of the HIV Seroconversion Window Period and False Positive Rate by Using ADVIA Centaur HIV Antigen/Antibody Combo Assay. Ann Lab Med 33: 420-425.

2. Cohen MS, Gay CL, Busch MP, Hecht FM (2010) The detection of acute HIV infection. J Infect Dis 202: S270-S277.

3. Hazenberg MD, Otto SA, van Benthem BH, Roos MT, Coutinho RA, et al. (2003) Persistent immune activation in HIV-1 infection is associated with progression to AIDS. AIDS 17: 1881-1888.

4. Okulicz JF, Lambotte $O$ (2011) Epidemiology and clinical characteristics of elite controllers. Curr Opin HIV AIDS 6: 163-168.

5. Lambotte O, Delfraissy JF (2006) HIV controllers: a homogeneous group of HIV-1 infected patients with a spontaneous control of viral replication. Pathol Biol (Paris) 54: 566-571.

6. Hunt PW, Brenchley J, Sinclair E, McCune JM, Roland M, et al. (2008) Relationship between T cell activation and CD4+ T cell count in HIVseropositive individuals with undetectable plasma HIV RNA levels in the absence of therapy. J Infect Dis 197: 126-133.

7. Phillips AN, Neaton J, Lundgren JD (2008) The role of HIV in serious diseases other than AIDS. AIDS 22: 2409-2418.

8. Tiemessen CT, Martinson N (2012) Elite controllers: understanding natural suppressive control of HIV-1 infection. CMC 30: 282-285.

9. World Health Organization (2016) Consolidated guidelines on the use of antiretroviral drugs for treating and preventing HIV infection: recommendations for a public health approach: $2^{\text {nd }}$ Edition, Geneva, Switzerland.

10. Promer K, Karris MY (2018) Current Treatment Options for HIV Elite Controllers: A Review. Curr Treat Options Infect Dis 10: 302-309.

11. National Department of Health South Africa (2019) ART Clinical Guidelines for the Management of HIV in Adults, Pregnancy, Adolescents, Children, Infants and Neonates. NDoH Pretoria.
12. Gebara NY, El Kamari V, Rizk N (2019) HIV-1 elite controllers: an immunovirological review and clinical perspectives. J Virus Erad 5: 163-166.

13. Woldemeskel BA, Kwaa AK, Blankson JN (2020) Viral reservoirs in elite controllers of HIV-1 infection: Implications for HIV cure strategies. EBioMedicine 62: 103118.

14. Rosás-Umbert M, Llano A, Bellido R, Olvera A, Ruiz-Riol M, et al. (2019) Mechanisms of abrupt loss of virus control in a cohort of previous HIV controllers. J Virol 93: e01436-e01518.

15. Jilg N, Garcia-Broncano P, Peluso M, Segal FP, Bosch RJ, et al. (2020) Maintenance of Viral Suppression in Human Immunodeficiency Virus Controllers Despite Waning T-Cell Responses During Antiretroviral Therapy. J Infect Dis 222: 1837-1842.

16. Noel N, Lerolle N, Lécuroux C, Goujard C, Venet A, et al. (2015) Immunologic and Virologic Progression in HIV Controllers: The Role of Viral "Blips" and Immune Activation in the ANRS CO21 CODEX Study. PloS one 10: e0131922.

17. National Department of Health (2016) National HIV Testing Services: Policy 2016. South Africa.

18. HIV/AIDS JUNPo (2017) Ending AIDS: Progress towards the $90-90-90$ targets.

19. Granich R, Williams B, Montaner J, Zuniga JM (2017) 90-90-90 and ending AIDS: necessary and feasible. Lancet 390: 341-343.

20. Group ISS (2017) Initiation of antiretroviral therapy in early asymptomatic HIV infection. N Engl J Med 373: 795-807.

21. Grabar S, Selinger-Leneman H, Abgrall S, Pialoux G, Weiss L, et al. (2009) Prevalence and comparative characteristics of long-term nonprogressors and HIV controller patients in the French Hospital Database on HIV AIDS 23: 1163-1169.

22. Crowell TA, Gebo KA, Blankson JN, Korthuis PT, Yehia BR, et al. (2015) Hospitalization Rates and Reasons among HIV Elite Controllers and Persons with Medically Controlled HIV Infection. J Infect Dis 211: 1692-1702.

23. Noël N, Saez-Cirion A, Avettand-Fenoël V, Boufassa F, Lambotte $O$ (2019) HIV controllers: to treat or not to treat? Is that the right question? THE LANCET HIV 6: e878-e884.

24. Chaix ML, Boufassa F, Meyzer C, Leruez-Ville M, Mahjoub N, et al. (2017) Detectable HIV-RNA in semen of HIV controllers. PloS one 12: e0183376.

25. Okulicz JF, Grandits GA, Weintrob AC, Landrum ML, Ganesan A, et al. (2010) CD4 T cell count reconstitution in HIV controllers after highly active antiretroviral therapy. Clin Infect Dis 50: 1187-1191.

26. Sedaghat AR, Rastegar DA, O'Connell KA, Dinoso JB, Wilke CO, et al. (2009) T cell dynamics and the response to HAART in a cohort of HIV-1-infected elite suppressors. Clin Infect Dis 49: 1763-1766.

27. Pereyra F, Palmer S, Miura T, Block BL, Wiegand A, et al. (2009) Persistent low-level viremia in HIV-1 elite controllers and relationship to immunologic parameters. J Infect Dis 200: 984-990.

28. Li JZ, Segal FP, Bosch RJ, Lalama CM, Roberts-Toler C, et al. (2020) Antiretroviral therapy reduces T-cell activation and immune exhaustion markers in human immunodeficiency virus controllers. Clin Infect Dis 70: 1636-1642. 